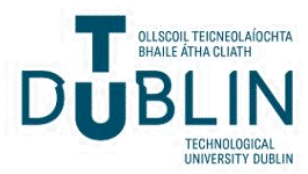

Technological University Dublin

ARROW@TU Dublin

2015-8

\section{A Simple Polarization Reconfigurable Printed Monopole Antenna}

\author{
Afshin Panahi \\ Technological University Dublin \\ Xiulong Bao \\ Technological University Dublin, xiulong.bao@tudublin.ie \\ Kansheng Yang \\ Technological University Dublin, kansheng.yang@mydit.ie
}

See next page for additional authors

Follow this and additional works at: https://arrow.tudublin.ie/ahfrcart

Part of the Systems and Communications Commons

\section{Recommended Citation}

A. Panahi, X. L. Bao, K. Yang, O. O'Conchubhair, and M. J. Ammann, "A Simple Polarization Reconfigurable Printed Monopole Antenna", IEEE Transactions on Antennas \& Propagation, vol. 63, issue 11, pp. 5129 5134, 08/2015. doi:10.1109/TAP.2015.2474745

This Article is brought to you for free and open access by the Antenna \& High Frequency Research Centre at ARROW@TU Dublin. It has been accepted for inclusion in Articles by an authorized administrator of ARROW@TU

Dublin. For more information, please contact

arrow.admin@tudublin.ie, aisling.coyne@tudublin.ie, gerard.connolly@tudublin.ie.

Funder: SFI/HEA

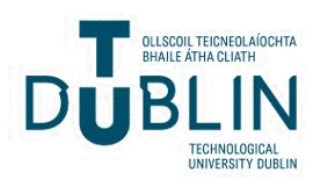




\section{Authors}

Afshin Panahi, Xiulong Bao, Kansheng Yang, Oisin O'Conchubhair, and Max Ammann

This article is available at ARROW@TU Dublin: https://arrow.tudublin.ie/ahfrcart/64 


\section{A Simple Polarization Reconfigurable Printed Monopole Antenna \\ A. Panahi, X. L. Bao, K. Yang, \\ O. O’Conchubhair and M. J. Ammann}

\begin{abstract}
A simple polarization reconfigurable printed monopole antenna is proposed for wireless applications. Conducting strips are used to connect to the ground plane providing the necessary additional modes for circular-polarization. Linear-polarization, right hand or left hand circular-polarization can be realized using only two PIN diodes, which connect to the ground plane, minimizing their effect on radiation characteristics. The mechanism is described, and key antenna parameters are studied and optimized. The antenna is prototyped and tested for all polarization configurations
\end{abstract}

Index Terms - Monopole antennas, polarization reconfigurable

\section{INTRODUCTION}

RECENTLY, reconfigurable antennas have seen increased development in devices because of their ability to dynamically provide frequency, pattern and polarization agility in a single antenna with the advantages of improved signal reception, reduced size and low-cost. Reconfigurable antennas have been realized by placing switching elements such as MEMS, varactor and PIN diodes on the antenna ground plane or radiator element. Polarization diversity antennas can mitigate the fading caused by multipath scenarios and inclement weather and thus are beneficial in satellite, mobile and wireless communications systems. Implementing polarization reconfigurability to increase channel capacity is also attractive in MIMO systems [1]. In recent years many reconfigurable microstrip patch antennas [2-4], slot antennas [5-6] and monopole antennas [7] were proposed to achieve polarization, frequency and pattern reconfiguration. However, to the best of our knowledge, only four polarization reconfigurable printed monopole antennas are reported from which, only two are circularly-polarized (CP) [8-9]. In [10] an L-shaped slot is created on the ground plane of the monopole antenna. Two copper pads (as switches) are used on the microstrip feed line and the L-shaped slot. The antenna generates vertical polarization when both switches are on and horizontal polarization when both switches are off. In [11] one of two orthogonal meandered elements is excited by a copper pad that connects to the microstrip feed lines. Depending on which

Manuscript received February 24, 2015. This work was part funded by the Irish Higher Education Authority under PRTLI Cycle 5 as part of the Telecommunication Graduate Initiative, SFI 10/CE/I1853 and SFI 14/TIDA/2479.

A. Panahi, K. Yang, O. O'Conchubhair, X. L. Bao, and M. J. Ammann are with the Antenna \& High Frequency Research Centre, School of Electrical \& Electronic Engineering, Dublin Institute of Technology, Dublin 8, Ireland (e-mail: afshin.panahi@mydit.ie; xbao@dit.ie kansheng.yang@mydit.ie; oisin.oconchubhair@mydit.ie; max.ammann@dit.ie).

Color versions of one or more of the figures in this paper are available online at http://ieeexplore.ieee.org.

Digital Object Identifier element is connected to the feed line, pattern reconfigurability of the antenna is achieved. In [8] a planar UWB monopole/slot with polarization reconfigurability is reported. Two vertical rectangular slots are embedded in the planar radiating element and 4 conducting strips across the slots are proposed to switch polarization from linear-polarization (LP) to right-hand circular-polarization (RHCP) or left-hand circular polarization (LHCP). Although UWB matching performance is achieved for $\mathrm{LP}$, this degrades for CP states. Conducting strips were used for proof-of-concept in this case. In [9] a polarization reconfigurable monopole antenna consisting of two orthogonal meandered arms, a feeding network with a Wilkinson power divider, two $90^{\circ}$ phase shifters and a defected ground plane is reported. The phase shifters, controlled by 6 PIN diodes, provide $0^{\circ}, 90^{\circ}$ and $-90^{\circ}$ phase difference between the antenna arms resulting in switchable LP, RHCP and LHCP for the monopole antenna.

In this paper, we propose a simple polarization reconfigurable printed monopole antenna for WLAN applications. It provides linear polarization as well as both RHCP and LHCP. The planar monopole is augmented by conducting strips, which connect to the ground plane using PIN diodes. It is less complex than [8-9] and has the advantage of avoiding diodes in the radiating element, with the benefit of using only 2 PIN diodes and a simple feed arrangement. To explain the $\mathrm{CP}$ mechanism and antenna concept, two copper pads are used initially. The pads are replaced by PIN diodes at a later stage and the antenna is slightly modified to minimize PIN diode and associated circuit effects. Key parameters are studied that show how polarization configurability is optimized.

\section{ANTENNA DESIGN AND ANALYSIS}

\section{A. Antenna structure and CP mechanism}

Fig.1 shows the antenna geometry and its dimensions. The antenna is printed on a Taconic substrate of dimension $35.2 \mathrm{~mm}$ $\times 67.5 \mathrm{~mm} \times 1.52 \mathrm{~mm}$ with $\varepsilon_{r}=3.5$ and $\tan \delta=0.0018$. The antenna consists of a rectangular-shaped planar monopole arm and a rectangular-shaped ground plane. The ground plane is augmented with two $3 \mathrm{~mm}$ wide strips $\left(S_{l}\right.$ and $S_{r}$ ) and separated by $1.75 \mathrm{~mm}(\mathrm{~g})$ from the upper edge of the ground plane. A small strip (p) of width $1.5 \mathrm{~mm}$ is used to reconfigure polarization by connecting the ground plane to the strips. The antenna is fed with a $50 \Omega$ microstrip line ( $3.5 \mathrm{~mm}$ wide) and optimized for circular polarization at $2.4 \mathrm{GHz}$. When the ground plane and strips are not connected, the induced surface current on the ground plane horizontal edges and the strips are in phase but oppositely directed, therefore cancel, leaving only the vertical surface currents on the monopole arm and ground plane, generating a linearly-polarized wave. When the ground plane is connected to one of the strips, the surface current on the ground plane and the strips are rearranged so that the instantaneous currents on the strips and the ground plane are in the same direction and form the horizontal component needed for CP generation. Fig. 2 shows the antenna surface currents with and without the copper strip (p). When the ground plane is connected to the right strip $\left(S_{r}\right)$, the antenna realizes RHCP in 
the $+\mathrm{Z}$ direction. When connected to the left strip $\left(S_{l}\right)$, LHCP is achieved in the same direction. Because the location of the connection (p) is symmetric with respect to the center of the coordinate system i.e. $x=0$, all the properties (axial ratio (AR), $\mathrm{S}_{11}$, gain, efficiency...) of the RHCP and LHCP antennas are the same except radiation patterns which are mirrored.

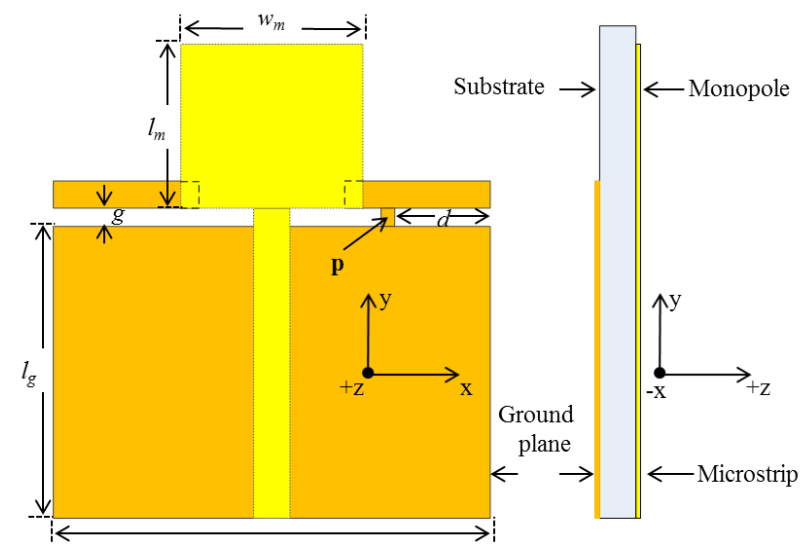

(a)

(b)

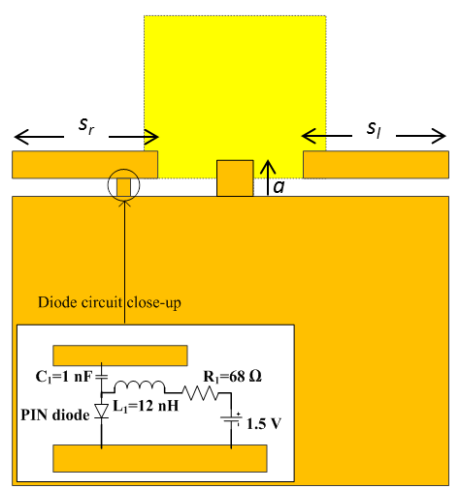

(c)

Fig.1. Antenna geometry (a) front view, (b) side view, (c) rear view of the antenna and the PIN diode and biasing circuit with : $l_{m}=23.2, w_{m}=24.7$, $l_{g}=39.3, w_{g}=65.2, s_{l}=s_{r}=21.5, g=1.75, d=11.5$ and $a=4 \mathrm{~mm}$.

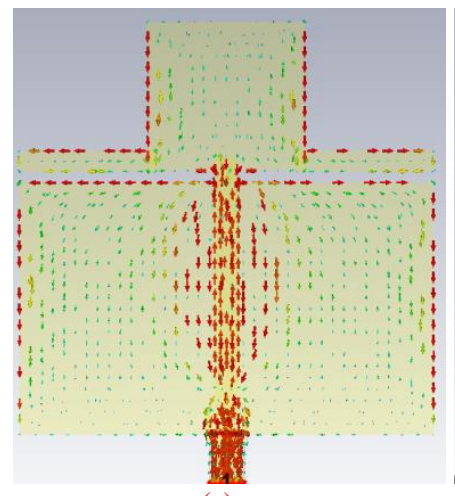

(a)

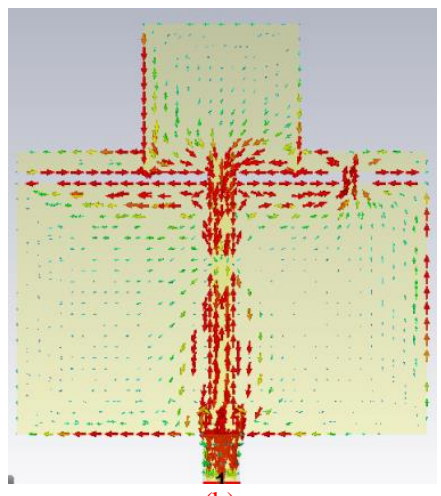

(b)
Fig. 2. Antenna surface current: (a) without copper strip,p and (b) with copper strip, p.

\section{B. Parametric study}

The parametric study is based on simulation using the CST MWS time-domain solver. As with all printed monopoles, the radiation is generated by currents on the antenna as a whole, so all components must be optimized. The ground plane is optimized for the intended $\mathrm{CP}$ frequencies and if a larger ground plane is employed, the AR and $\mathrm{S}_{11}$ will degrade and the radiation properties will change. In particular, the AR shows greater sensitivity to ground plane width because of the horizontal component dependence. The antenna AR is particularly sensitive to the length of the strips $S_{l}, S_{r}$, the gap $g$, and the location $d$ where the strips connect to the ground plane. The $S_{11}$ is also affected by the same parameters. Figs 3(a) and 3(b) show the sensitivity of the $S_{11}$ and AR to variation in $d$. The effect of changing the length of $S_{r}$ and $S_{l}$ (for $d=11.5 \mathrm{~mm}$ ) on the $S_{11}$ and the AR are presented in Figs 4(a) and 4(b), respectively. The gap $(g)$ between the strips (also the monopole) and the ground plane is another key parameter in the optimization. The AR and $\mathrm{S}_{11}$ dependence on $g$, (for $d=11.5$ $\mathrm{mm}$ ), is shown in Figs 5(a) and 5(b). While the antenna is optimized for AR at $2.4 \mathrm{GHz}$, the $\mathrm{S}_{11}$ of the $\mathrm{CP}$ antenna is only $-9 \mathrm{~dB}$. To improve the matching, a $3.5 \mathrm{~mm}$ wide strip with a length of $a$ is added to the upper edge of the ground plane directly behind the feed line. This strip improves the matching without any changes in AR. As seen in Figs 3-5 the AR and $S_{11}$ are heavily dependent on the parameters, $d, g, S r$ and $S_{l}$, which are key in providing equal magnitude of horizontal and vertical components as well as the required phase-time difference.

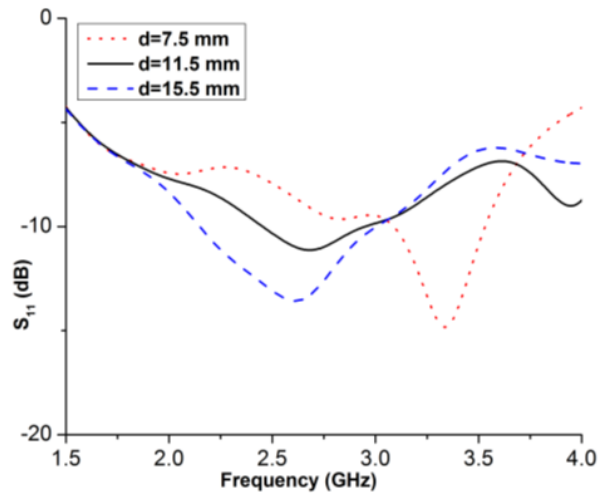

(a)

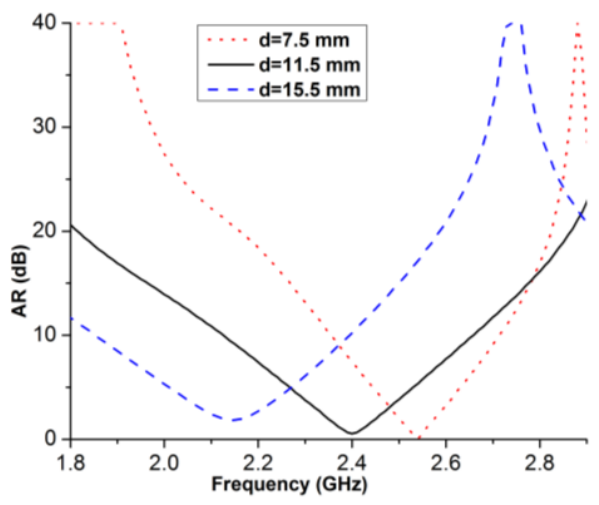

(b)

Fig. 3. Sensitivity of (a) $\mathrm{S}_{11}$ and (b) AR to the copper strip location, $d$. 


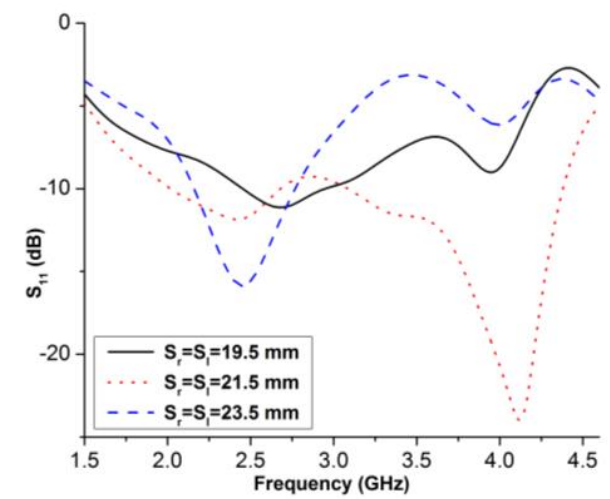

(a)

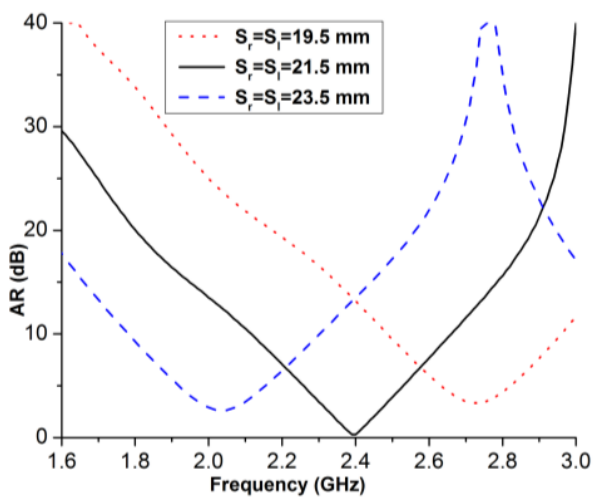

(b)

Fig. 4. Simulated (a) $S_{11}$ and (b) AR variation with length of strips $s_{r}, s_{l}$.

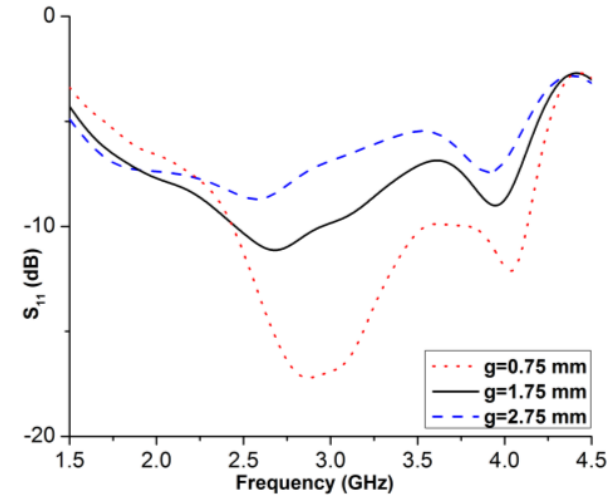

(a)

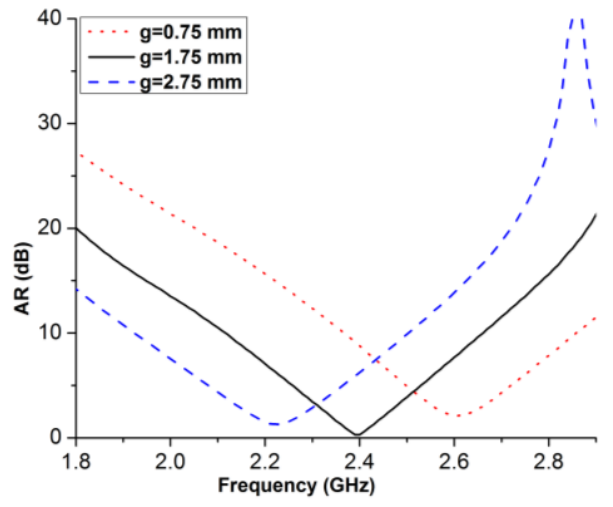

(b)

Fig. 5. Simulated (a) $\mathrm{S}_{11}$ and (b) AR dependence on $g$.

\section{Antenna with PIN diodes and biasing circuit}

A PIN diode is employed on each side of the antenna which replaces the copper strip, p. This allows polarization switching from RHCP to LHCP and vice versa when one PIN diode is forward biased. The antenna is LP when both PIN diodes are off. The PIN diode (SMP1320-011LF) and biasing circuit are shown in Figure 1(c). A 1.5 Volt button battery (SR44) is used to power the diode. $R 1$ is used as current limiter; $L 1$ is an RF choke and $C 1$ is a DC block. In CST, the PIN diode is simulated as a $0.75 \Omega$ resistor and $1.5 \mathrm{nH}$ inductor when forward biased $(\mathrm{ON})$. When reverse biased (OFF), it works as a $0.75 \Omega$ resistor and $0.23 \mathrm{pF}$ capacitor, as specified in the data sheet. In this design, the PIN diode connects to the ground plane, thus minimal loss is introduced. Although the upper strip works as the RF ground, $C 1$ needs to be added to remove the DC potential difference. The replacement of the copper strip with one PIN diode in the ON state causes a downward frequency shift in both $S_{11}$ and $A R$ due to the additional capacitance as seen in Figs 6 (a) and 6 (b). This can be rectiified by making minor changes to either of the key parameters studied previously. Here, for simplicity, $S_{r}$ and $S_{l}$ are shortened by 1.9 $\mathrm{mm}$. The introduction of the PIN diode also influences the radiation pattern direction and decreases the gain across the AR bandwidth at $\theta=0^{\circ}$ (see Fig. 10 (b)). A peak CP gain of 1.74 $\mathrm{dBic}$ at $\theta=0^{\circ}, \varnothing=-5$ is realized for the antenna with copper strip while the antenna with PIN diodes achieves a gain of 1.55 $\mathrm{dBic}$ at $\theta=325^{\circ}, \emptyset=-15^{\circ}$. The maximum radiation efficiency is $-0.18 \mathrm{~dB}$ for the copper case and this drops to $-0.23 \mathrm{~dB}$ with the PIN diode in circuit at $2.4 \mathrm{GHz}$. The total efficiency also decreases slightly across the $3 \mathrm{~dB}$ AR bandwidth e.g. at 2.4 $\mathrm{GHz}$, the simulated total efficiency drops from $-0.38 \mathrm{~dB}$ (copper strip) to $-0.5 \mathrm{~dB}$ (PIN diode).

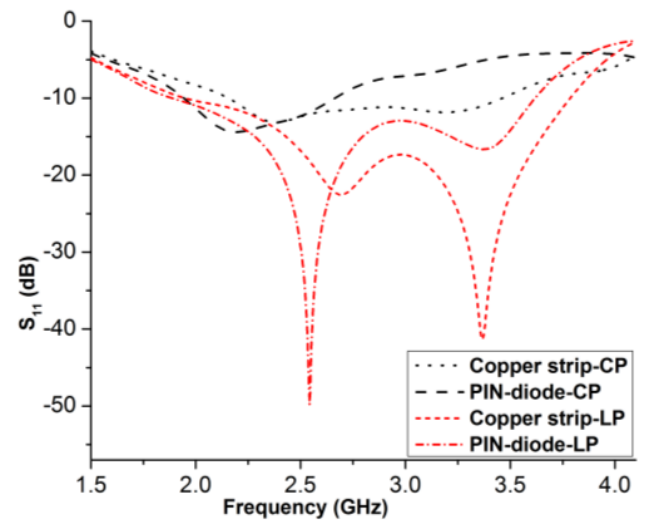

(a)

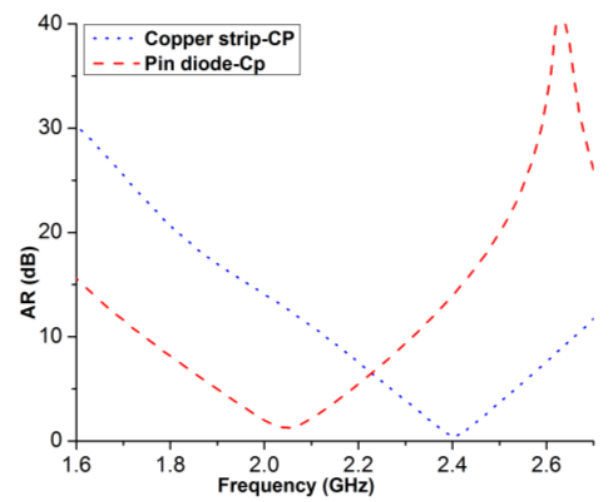

(b)

Fig. 6. Comparison of (a) the $\mathrm{S}_{11}$ and AR for the CP \& LP antennas and (b) the AR for copper strip vs PIN diode. 


\section{RESULTS AND DISCUSSION}

The prototyped antenna is shown in Fig. 7(a, b). Fig. 8 (a, b) shows the measured and simulated $\mathrm{S}_{11}$ of the proposed reconfigurable antenna in the LP, RHCP and LHCP configurations. The measured and simulated AR for RHCP and LHCP antennas are shown in Fig. 9. The measured and simulated $\mathrm{S}_{11}$ bandwidth for the LP configuration is from 1.91 to $4.00 \mathrm{GHz}(70 \%)$ and from 1.95 to $3.80 \mathrm{GHz}(64 \%)$, respectively. The RHCP and LHCP antennas have an identical simulated $\mathrm{S}_{11}$ bandwidth of $22 \% \quad(2.00-2.50 \mathrm{GHz})$. The measured $-10 \mathrm{~dB} S_{11}$ band covers a range from 2.00 to 2.52 $\mathrm{GHz}(23 \%)$ and 2.10 to $2.54 \mathrm{GHz}(19 \%)$ for RHCP and LHCP, respectively. The simulated $3 \mathrm{~dB}$ AR for both RHCP and LHCP configurations is $7 \%(2.30-2.47 \mathrm{GHz})$ and the measurement results show a $3 \mathrm{~dB}$ AR from 2.34 to $2.46 \mathrm{GHz}(4.5 \%)$ in the RHCP case and of $4.4 \%(2.33-2.44 \mathrm{GHz})$ for the LHCP case. The radiation patterns of the $\mathrm{LP}$ and $\mathrm{CP}$ antennas in the $\mathrm{XZ}$ and YZ planes for $2.4 \mathrm{GHz}$ are shown in Figs 10 (a-b) and 11 (a-d). The measured $3 \mathrm{~dB}$ beamwidth in the RHCP configuration is $115^{\circ}$ with a measured peak gain of $1.2 \mathrm{dBic}$ at $315^{\circ}$. The measured beamwidth in the LHCP configuration was $110^{\circ}$ with a realized peak gain of $0.6 \mathrm{dBic}$ at $40^{\circ}$. Measured values for the $\mathrm{AR}$ and radiation patterns, in all configurations, were obtained in the broadside direction i.e. $\theta=0^{\circ}$.

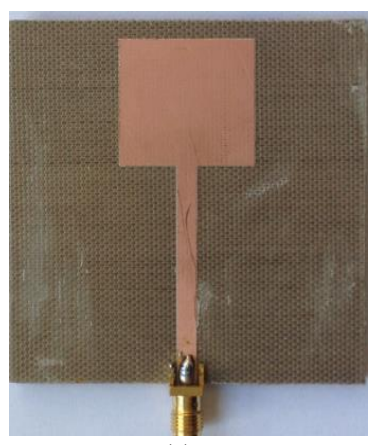

(a)

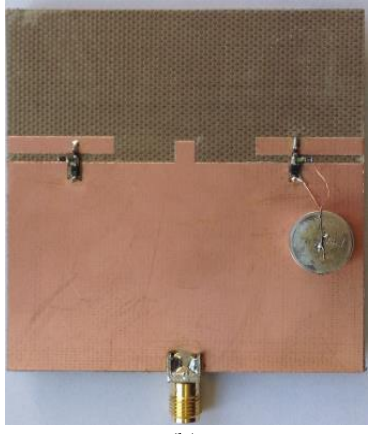

(b)
Fig. 7. Prototyped antenna: (a) front view and (b) rear view.

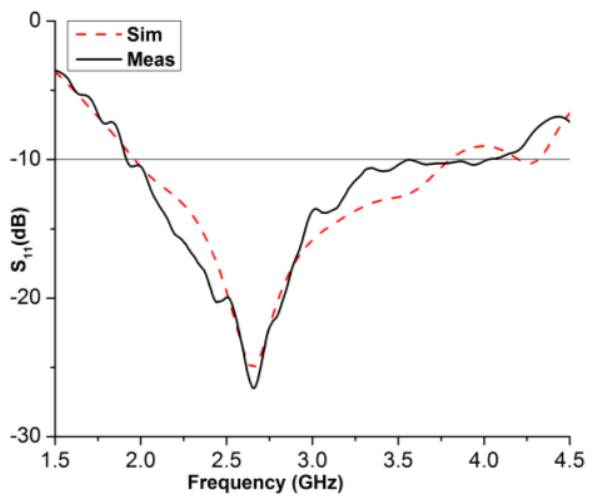

(a)

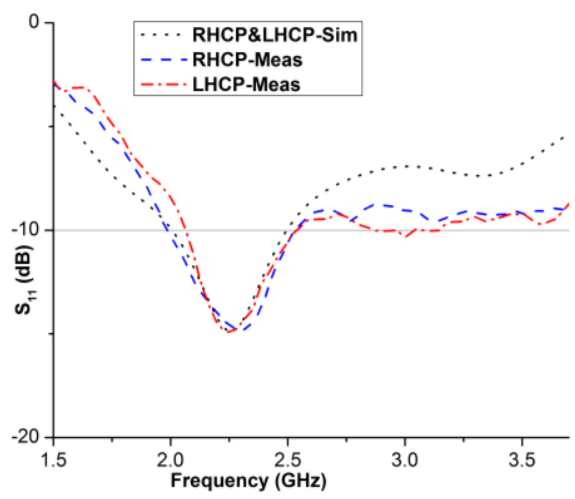

(b)

Fig. 8. Measured and simulated $\mathrm{S}_{11}$ for (a) LP and (b) RHCP and LHCP configurations.

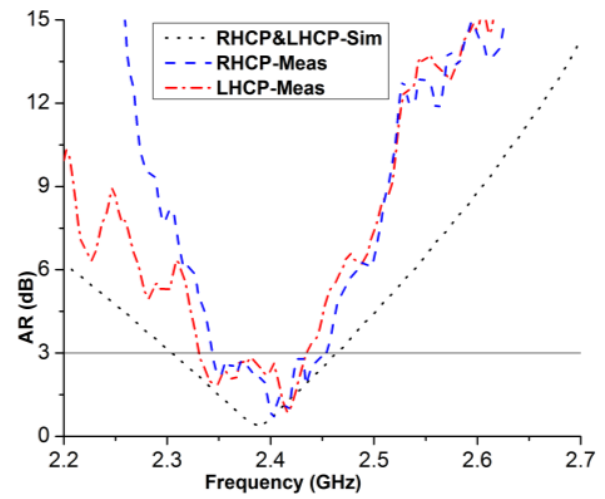

Fig. 9. Measured and simulated AR for RHCP and LHCP configurations.

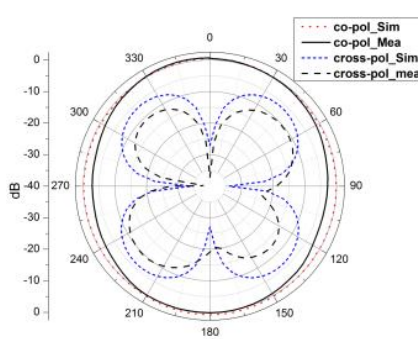

(a)

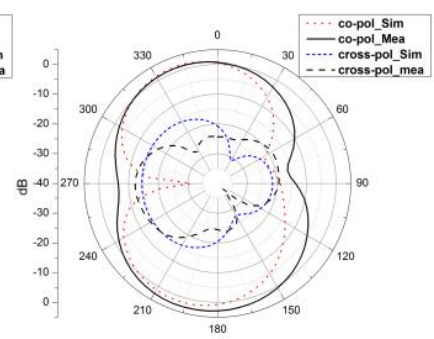

(b)
Fig. 10. Radiation patterns for the LP configuration: (a) in $\mathrm{XZ}$ and (b) $\mathrm{YZ}$ planes at $2.4 \mathrm{GHz}$.

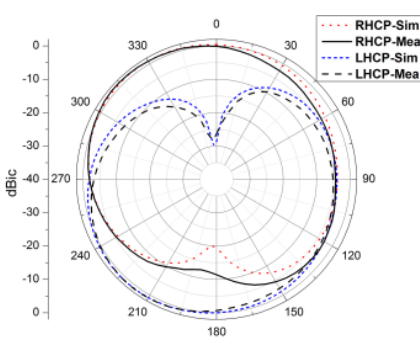

(a)

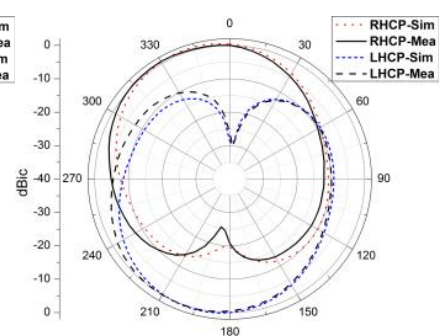

(b) 


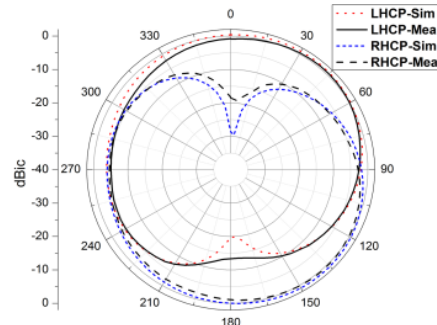

(c)

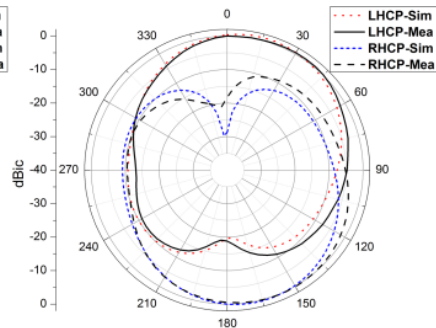

(d)
Fig. 11. Radiation patterns for the CP configurations: (a) RHCP in XZ plane and (b) in YZ planes and (c) LHCP in XZ and (d) in YZ planes at $2.4 \mathrm{GHz}$.

There is good agreement between simulation and measurement. Fig. 12 (a) represents the simulated and measured gain for LP case. Fig. 12 (b) shows the simulated realized gain of the $\mathrm{CP}$ antenna with copper strip and also the measured and simulated boresight gain for RHCP and LHCP configurations. The PIN diodes are simulated as ideal lumped components without considering the actual P-I-N junction and depletion region. This results in a gain drop between measured and simulated realized gain.

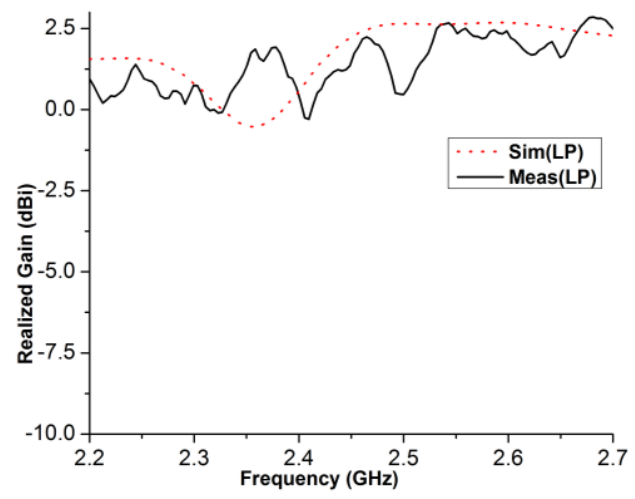

(a)

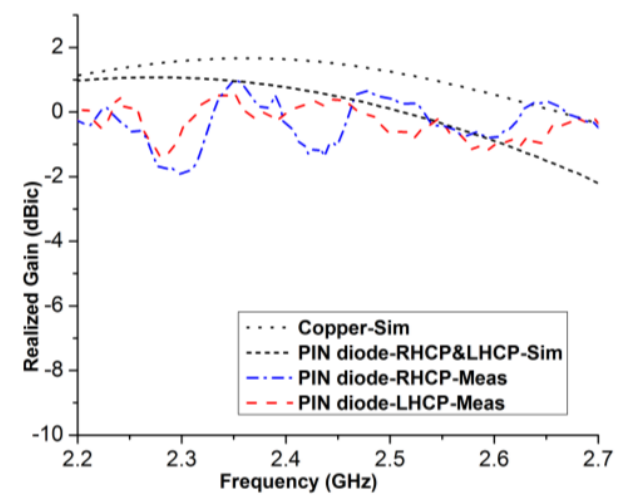

(b)

Fig. 12. Measured and simulated boresight gain of (a) the LP PIN diode antenna and (b) the RHCP and LHCP configurations and simulated realized gain of the $\mathrm{CP}$ antenna with copper strip.

\section{CONCLUSION}

A simple low-cost printed monopole antenna with polarization reconfiguration for WLAN applications is proposed. It can provide LP as well as RHCP or LHCP configurations using only two PIN diodes. The diodes connect to the ground plane minimizing their influence on radiation characteristics. The antenna has a measured AR bandwidth of $4.5 \%$ and $4.4 \%$ for RHCP and LHCP configuration, respectively. The measured realized gain is $1.2 \mathrm{dBic}, 0.6 \mathrm{dBic}$ and $0.5 \mathrm{dBi}$ for the RHCP, LHCP and LP configurations at 2.4 $\mathrm{GHz}$.

\section{REFERENCES}

[1] D. Piazza, P. Mookiah, M. D'Amico, and K. R. Dandekar, "Experimental Analysis of Pattern and Polarization Reconfigurable Circular Patch Antennas for MIMO Systems", IEEE Transactions on Vehicular Technology, 59, (5), pp. 2352-2362, 2010

[2] L. Ge, and K.M. Luk," Frequency-Reconfigurable Low-Profile Circular Monopolar Patch Antenna", IEEE Transaction on Antennas and Propagation, 62, (7), pp. 3443-3449, 2014

[3] A. Khidre, K. F. Lee, F. Yang, and A. Z Elsherbeni, "Circular Polarization reconfigurable E-Shaped Patch Antennas for Wireless Applications", IEEE Transactions on Antennas and Propagation, 61, (2), pp. 960-964, 2013

[4] P. Y. Qin, A. R. Weily, Y. J. Gue, and C. H. Liang, "Polarization Reconfigurable U-Slot Patch Antenna", IEEE Transaction on Antennas and Propagation, 58, (10), pp. 3383-3388, 2010

[5] Y. Lee, Z. Zhang, W. Chen, and Z. Feng, "Polarization Reconfigurable Slot Antenna With a Novel Compact CPW-to-Slotline Transition for WLAN Application", IEEE Antennas and Wireless Propagation Letters, 9, pp. 252-255, 2010

[6] S.V.Shynu \& M. J. Ammann," Reconfigurable Antenna with Elevation and Azimuth Beam Switching, IEEE Antennas \& Wireless Propagat. Letters, 2010, (9), 367-370.

[7] R. Gonçalves, P. Pinho, and N. B. Carvalho, "Compact, Frequency Reconfigurable, Printed Monopole Antenna," International Journal of Antennas and Propagation, vol. 2012, Article ID 602780, 6 pages, 2012 doi: $10.1155 / 2012 / 602780$.

[8] T. Aboufoul, A. Alomainly, and C. Parini, "Polarization Reconfigurable Ultra Wideband Antenna for Cognitive Radio Devices", IEEE Antennas and Propagation Society International Symposium (APSURSI), pp. 1636-1637, 2013

[9] Y. F. Cao, S. W. Cheung, and T. I. Yuk, “ A Simple Planar Polarization Reconfigurable Monopole Antenna for GNSS/PCS”, IEEE Transactions on Antennas and Propagation, 63, (2), pp. 500-507, 2015.

[10] M. H. Amiri, H. R. Hassani, and S. Mohammadi ali nezhad, "A Single Feed Reconfigurable Polarization Printed Monopole Antenna", 6th European Conference on Antennas and Propagation (EuCAP), pp. 1-4, 2012

[11] S. Raman, P. Mohanan, N. Timmons, and J. Morrison, “ Microstrip-Fed Pattern - and Polarization-Reconfigurable Compact Truncated Monopole Antenna" IEEE Antennas and Wireless Propagation Letters,12, pp. 710-713, 2013 